\title{
Management of patients with metastatic colorectal cancer in Lebanese hospitals and associated direct cost: a multicentre cohort study
}

Anna Maria Henaine, ${ }^{1,2,5}$ Georges Chahine, ${ }^{4}$ Marcel Massoud,,${ }^{4,9}$ Pascale Salameh,,${ }^{5,7}$ Sanaa Awada, ${ }^{5}$ Nathalie Lahoud,${ }^{8}$ Edward Elias, ${ }^{4}$ Mansour Salem, Souheir Ballout, ${ }^{5}$ Daniel Hartmann, ${ }^{1,2}$ Gilles Aulagner ${ }^{1,2,3}$ and Xavier Armoiry ${ }^{1,2,3,6}$

${ }^{1}$ Université Claude Bernard Lyon ${ }^{1}$, Lyon, France. ${ }^{2}$ UMR-CNRS 5510/MATEIS, Lyon, France ${ }^{3}$ Hospices Civils de Lyon, Hôpital Édouard-Herriot, Service Pharmaceutique, Lyon, France. ${ }^{4}$ Hôtel Dieu de France and St Joseph University, Beirut; Hôpital Notre Dame de Secours, Byblos, Lebanon. ${ }^{5}$ Clinical and Epidemiological Research Laboratory, School of Pharmacy, Lebanese University, Beirut, Lebanon. ${ }^{6}$ University of Lyon, Claude Bernard University Lyon, ${ }^{3}$ Lyon School of Pharmacy, Public Health Department, Lyon, France, ${ }^{7}$ Pharmacy Practice Department, School of Pharmacy, Lebanese American University, Beirut, Lebanon. ${ }^{8}$ Doctoral School of Sciences and Technologies, Lebanese University, Beirut, Lebanon. ${ }^{9}$ Holy Spirit University,Kaslik, Lebanon. (Correspondence to: Anna Maria Henaine: annamaria.henaine@gmail.com).

\begin{abstract}
Background: For metastatic colorectal cancer a series of novel therapies has emerged during the last decade but their use in routine clinical practice and their costs are not well documented.
\end{abstract}

Aims: This study evaluated the clinical effectiveness of metastatic colorectal cancer patients in Lebanese oncologic units and estimated the costs.

Methods: A prospective cohort study was conducted on metastatic colorectal cancer patients during 2008-2013. The type of medical management, overall survival and total costs from diagnosis to death were described. Cost analysis was performed using tariffs from 2013 in US dollars.

Results: One hundred and seventy-nine metastatic patients were selected among which $84.9 \%$ had colorectal cancer involvement. The average follow-up from diagnosis until death or the latest news was 34.8 months. Around $49.7 \%$ were still alive at last follow-up date. Three lines of treatment accounted for $4.5 \%, 39.6 \%$ and $55.9 \%$ with an average duration of 14.5, 11.4 and 14.6 months respectively. A $73.2 \%$ of patients benefited from targeted therapy. The median overall survival was 20.8 months. The mean total costs of drugs was $\$ 22256$ in patients with standard therapy alone whereas the cost increased to $\$ 80396$ after the addition of targeted therapy. The mean global total cost was estimated at $\$ 64805$ per patient (min \$3703; max \$304 086).

Conclusions: Targeted therapy associated to standard therapy is highly prevalent in Lebanon in metastatic disease and the associated medical cost substantial. This study is the first to show the clinical effectiveness and costs of targeted therapy in patients with metastatic colorectal cancer.

Keywords: metastatic colorectal cancer, cytotoxic agents, targeted therapies, effectiveness, cost.

Citation: Henaine AM; Chahine G; Massoud M; Salameh P; Awada S; Lahoud N et al. Management of patients with metastatic colorectal cancer in Lebanese hospitals and associated direct cost: a multicentre cohort study. East Mediterr Health J. 2019;25(7):481-494. https://doi.org/10.26719/emhj.18.063 Received: 28/03/17; accepted: 18/02/18

Copyright (C World Health Organization (WHO) 2019. Some rights reserved. This work is available under the CC BY-NC-SA 3.0 IGO license (http://creativecommons.org/licenses/by-nc-sa/3.o/igo ).

\section{Introduction}

Colorectal Cancer is the second most commonly reported cancer in females and the fourth most commonly reported cancer in males in Lebanon, averaging 630 cases in 2012 (1). There are no vital statistics or information on the burden of the disease in terms of morbidity or mortality, but its incidence rate in 2015 per 100000 population, by colon and rectum sites, was $17.6 \%$ and $7.5 \%$ respectively (2). In the Lebanese medical system, analysis of colorectal cancer is not robust and there has been a noticeable increase in risk factors such as poor diet, physical inactivity, obesity, cigarette smoking, heavy alcohol consumption, familial history and genetics. Moreover, the health financing methods are complex and vary according to socio-professional demographics $(3,4)$.

Despite these problems mortality rates have declined since the 1980s. Clinical evidence suggests that advances in technology, increase in number of colonoscopy examinations, more opportunistic screening, earlier diagnosis and improved surgery, development of adjuvant chemotherapy and palliative care (5), confer survival benefits as well as better symptom control and palliation. Cytotoxic agents are well established as clinically effective and cost-effective treatment options for metastatic colorectal cancer. Clinical research has focused on monoclonal antibodies that selectively target receptors involved in cancer progression with many studies evaluating their efficacy $(6-10)$.

As new treatments become available (11), there's a need to consider not only their effectiveness in clinical practice, but also their associated costs in comparison to current standard therapies. The way such novel therapies are used and positioned in daily routine practice (as well as their related effectiveness and costs) are not well documented in Lebanon. The aim of this study is to evaluate the management of patients with metastatic colorectal cancer in two Lebanese hospitals, in particular 
the comparative effectiveness of cytotoxic agents and targeted therapy along with their estimated direct cost.

\section{Methods}

\section{Study design and participants}

A prospective study was conducted on a cohort of patients diagnosed with metastatic colorectal cancer in two Lebanese oncology departments (CHU Centre Hospitalier Notre Dame de Secours, Byblos, and CHU Hotel Dieu de France, Beirut) between 1 January 2008 and 31 December 2013. Patients were classified as those treated by cytotoxic agents alone during the whole follow-up period and those treated at any time during their follow-up by chemotherapy plus monoclonal antibodies, depending on disease progression. Eligible participants were all patients with a histologically confirmed adenocarcinoma of the colorectum, with one or more metastases and no previous chemotherapy for metastatic disease. The ethic committees of the two participating centers waived the need for approval since the study was retrospective, anonymous and respected the individuals' confidentiality.

\section{Clinical data}

For each patient, data were collected for sex, age at diagnosis, date of the beginning of metastatic disease, type of cancer, histological type, KRAS (Kirsten Rat sarcoma viral oncogene) status, tumor markers, number and type of metastases, and whether it was first, second or third relapse. Patterns of care were described, type of medical management at diagnosis and after recurrence. The type of chemotherapy, RECIST (Response Evaluation Criteria In Solid Tumors) criteria, toxicities, the date of the latest news and/or death, as well as the number of lines and cycles of chemotherapy given were also reported.

\section{KRAS assessments}

The mutation status of the KRAS gene is linked to increased tumor aggressiveness, resistance to therapy and poor survival rate (12). Detection of KRAS status has become part of the standard work-up of patients with metastatic colorectal cancer, and tumors that harbor the mutation have been shown to be nonresponsive to anti-EGFR (Epidermal Growth Factor Receptor) therapies (Cetuximab) $(4,13-16)$. This test is performed in the Pathology National Institute, Beirut, Lebanon, in formalin-fixed, paraffin-embedded tissue collected from patients for whom the resected primary tumor was available and is free-of-charge, likewise the RAS test, but the BRAF test is expensive (these two tests have been performed in Lebanon since 2014).

\section{Lines of therapy}

Most patients with advanced colorectal cancer can receive multiple treatment regimens, with therapies changed when needed in order to optimize response or as a consequence of toxicity, patient preference, or disease progression. New options are chosen in a way that is complementary to the previous regimen. In order to prevent confusion, first-line therapy was defined as all chemotherapy and/or biological drugs given to a patient during the first 36 days after initiation of treatment and administered for one or more cycles. Discontinuation of a single drug from a combination regimen was not considered a change in line therapy. The addition of a new regimen or substitution of cytotoxic or a biological agent (for progression or relapse) was considered a new line of therapy.

\section{Costs}

Estimating the cost of colorectal cancer treatments in Lebanon is very difficult, mainly due to differences in coverage systems (Ministry of Health, National Social Security Funds, Lebanese Army, private patients, insurances etc.), and changes in prices between 2008 and 2013. Cost analysis was performed under the Lebanese Sickness Fund perspective using tariffs from 2013 in US dollars without any discount rate applied and included:

- Direct costs, as defined as chemotherapy medications (and biotherapy), costs per treatment cycle and total costs per patient. We did not include the cost of administration, supportive medications, physician consultations or treatment of complications. Chemotherapy treatment doses were given proportionally to body surface area.

- Indirect costs (transportation costs, surgery, imaging tests) have not been taken into account due to difficulties in accessing administrative medical records.

We assessed the episodes of care costs in the period considered (protocols and lines during hospitalizations and at home). The unit costs from 2013 were obtained from the cost accounting system of the two hospitals regardless of the coverage system of each patient. Cost values in this year were considered to be representative of the study period. Assigning the same year-specific cost unit to each healthcare service, any differences in cost over time would reflect changes in resource utilization and not in price deviations arising from pharmaceutical companies' policies or different production structures over the study period. Taking into account the date of each care episode and service, monthly costs were assessed (cost histories), and the year of diagnosis was considered the baseline year (Year Zero).

Long-term or lifetime costs are defined as the cumulative cost from the date of diagnosis to the date of death, but in long-term cost estimations some patients are not actually followed until their death, therefore these cost histories are censored (13,17-19). However, this introduces a problem; total cost is underestimated when based on the full sample of censored and non-censored cases, since patients who withdraw from the study, or who remain alive at the end of the follow-up period, will continue to incur costs after the study is over. On the other hand, if long-term cost is only estimated for patients with uncensored costs, the estimator is biased towards patients with shorter survival times because 
longer survival times are more likely to be censored. Therefore, censored data can lead to biased estimates if the appropriate analysis techniques are not used.

Effectiveness was evaluated by overall survival corresponding to the mean time from diagnosis to death (or date of last follow-up at time of data collection). Primary endpoints were overall survival, progression free survival (PFS), RECIST, progression of the disease (PD) or tumour response rate (TRR), response rate (RR), disease control rate (DCR) and costs.

\section{Tumour assessments}

Therapy response in solid tumours was assessed by measuring change in tumour size. RECIST is a standard measurement method that evaluates response to therapy by computed tomographic scans (CT) $(13,17-18,20)$. However CT scans do not permit characterization of tumour heterogeneity and its change over time. CT measurements are dependent on the expertise of the observer and discrepancies among observers have been described to be as high as 15 to $40 \%(19-20)$. Baseline tumour response was assessed every two cycles (6 weeks) according to RECIST version 1.1 (21-22) and all patients were monitored every three months for a minimum of two years.

\section{Definition of endpoints}

In this study, the following definitions were used to assess therapeutic effectiveness: PFS is defined as the time from randomization until objective tumour progression or death from any cause, and censoring patients who are lost to follow-up; PFS1 is the period from the first enrollment to the confirmation of $\mathrm{PD}$, death or last follow up, whichever occurred first; PFS2 is the period from the first $\mathrm{PD}$, where mostly biological agents were started, to the confirmation of secondary PD or death; PFS3 is the period from the second confirmation of PD to the third PD or death, where a third line (or salvage) therapy was used; time to tumor progression (TTP) is the period from the date of enrollment until the date of discontinuation of treatment or the date of PD confirmation (it does not count patients who die from other causes); overall response rate (ORR) is the sum of partial responses plus complete responses and is a direct measure of drug antitumor activity (direct therapeutic effect); and disease control rate (or rate of non-progression) is classified as complete response, partial response, or stable disease.

\section{Statistical analysis}

Categorical variables were presented as counts and percentages and compared using Pearson's chi-squared test or Fisher's exact test, as appropriate. Quantitative variables were presented as mean \pm standard deviation and compared using Student's t-test. Time since diagnosis was used as time variable. We compared patients' characteristics between groups, progression according to lines used and their relative costs.

In order to compare the effect of therapies (cytotoxic vs target + cytotoxic) on survival, a Cox proportional hazards regression was conducted to assess independent predictors of time to death after colorectal cancer. Patients were reported alive or dead at the end of their follow-up time. Variables associated to the time to death in the bivariate analysis $(P<0.2)$, were included in the multivariate model. Hazard ratios (HR) with $95 \%$ confidence intervals (CI) were reported.

Each variable was used as a time-dependent covariate in a cox bivariate regression to evaluate the proportional hazards assumption, which was subsequently confirmed and we compared the overall effect of both groups on survival. We subsequently conducted a sensitivity analysis between every line of treatment and its association with survival. Survival curves were then plotted to show differences in survival for each type of treatment. In addition, the response scores (RECIST) were divided into dichotomous variables (progression vs non-progression, partial or complete response) to study the effect of treatment (cytotoxic vs target) on disease progression (RECIST 1, 2 and 3). For this purpose, a logistic regression was conducted for each RECIST, taking into consideration variables found to be associated with the dependent variable in the bivariate analysis $(P<0.2)$. Analyses were performed using SPSS software, version 20.0 (IBM Corp., Armonk, NY, USA) and a P-value less than 0.05 was deemed statistically significant.

\section{Results}

\section{Study process and termination}

A total of 179 patients were enrolled between January 2008 and December 2013. Mean age at diagnosis was 60.5 $( \pm 13.2)$ years and $57.5 \%$ were males. The final follow-up of the study was on 30 December 2014 (the median follow up time was 31 months). The details of the baseline patient demographics and clinical characteristics are shown in Table 1.

\section{Treatments}

Among the 179 patients diagnosed with metastatic colorectal cancer, as first-line treatment 48 patients were provided chemotherapy alone while 131 patients received chemotherapy plus targeted therapy. After disease progression, and regardless of what regimen was used, 171 (95.5\%) went on to receive second-line treatment and 99 (55.3\%) received third-line treatment. Table 2 shows that targeted therapy was mostly added to treat aggressive disease ( 14 vs $86 \%, 58$ vs $42 \%, 89$ vs $11 \% ; P<0.001$ ) in association to cytotoxic conventional treatment.

Bevacizumab was mostly added to fluorouracil-based regimens in the first-line setting and beyond progression $(13.0 \%, 47.3 \%$ and $84.4 \%$; line 1 to 3 respectively) whereas Cetuximab was only restricted to patients whose KRAS status was performed and showed a non-mutant gene (1.1\%, 9.4\% and $15.6 \%$; line 1 to 3 respectively) (Table 2 ).

\section{Clinical effectiveness and survival}

Adding targeted therapy to conventional treatment did not improve the response rate in patients presenting pro- 


\begin{tabular}{|c|c|c|c|c|}
\hline Characteristics & Total (\%) & Cytotoxic group (N/\%) & $\begin{array}{l}\text { Cytotoxic + } \\
\text { targeted group } \\
(\mathbf{N} / \%)\end{array}$ & $P$-value \\
\hline Arms of treatment & 179 & $48(26.8 \%)$ & $131(73.2 \%)$ & - \\
\hline $\begin{array}{l}\text { Age at diagnosis, years } \\
\text { Range }\end{array}$ & $26-89 y$ & $27-83 y$ & $26-89 y$ & \\
\hline Mean $^{1}$ & $60.5 y \pm 13.2$ & $63 \mathrm{y} \pm 14.1$ & $59.5 y \pm 12.9$ & 0.130 \\
\hline \multicolumn{5}{|l|}{ Sex } \\
\hline Males/females & $103(57.5 \%) / 76(42.5 \%)$ & $28(58 \%) / 20(42 \%)$ & $75(57 \%) / 56(43 \%)$ & 0.947 \\
\hline \multicolumn{5}{|l|}{ Location of primary tumour } \\
\hline Colorectal & $152(84.9 \%)$ & $38(79 \%)$ & $114(87 \%)$ & \multirow{2}{*}{0.470} \\
\hline Rectal & $60.5 y \pm 13.2$ & $63 y \pm 14.1$ & $59.5 y \pm 12.9$ & \\
\hline \multicolumn{5}{|l|}{ Location of metastases } \\
\hline Liver only & $50(28 \%)$ & $21(44 \%)$ & $29(22 \%)$ & \multirow{3}{*}{0.002} \\
\hline Liver and others & $76(43 \%)$ & $8(17 \%)$ & $68(52 \%)$ & \\
\hline Non liver & $53(29 \%)$ & $19(39 \%)$ & $34(26 \%)$ & \\
\hline \multicolumn{5}{|l|}{ Number of metastatic sites } \\
\hline 1 & $92(52 \%)$ & $40(85 \%)$ & $52(40 \%)$ & \multirow[b]{2}{*}{0.044} \\
\hline$\geq 2$ & $86(48 \%)$ & $7(15 \%)$ & $79(60 \%)$ & \\
\hline \multicolumn{5}{|l|}{ KRAS gene status } \\
\hline Wild & $93(52 \%)$ & $11(23 \%)$ & $82(63 \%)$ & \multirow{3}{*}{0.001} \\
\hline Mutated & $27(15.1 \%)$ & $2(4 \%)$ & $25(19 \%)$ & \\
\hline $\mathrm{ND}^{*}$ & $59(33 \%)$ & $35(73 \%)$ & $24(18 \%)$ & \\
\hline \multicolumn{5}{|l|}{ Tumour markers } \\
\hline CEA only & $55(31 \%)$ & $10(21 \%)$ & $45(34 \%)$ & \multirow{4}{*}{0.001} \\
\hline CA19.9 only & $11(6 \%)$ & $3(6 \%)$ & $8(6 \%)$ & \\
\hline Both increased & $50(28 \%)$ & $7(15 \%)$ & $43(33 \%)$ & \\
\hline Neither increased & $63(35 \%)$ & $28(58 \%)$ & $35(27 \%)$ & \\
\hline $\begin{array}{l}\text { Duration of treatment or follow up (in } \\
\text { months) } \\
\text { (All lines combined) }\end{array}$ & $\begin{array}{c}\text { Median: } 30.9 \text { months } \\
\text { Mean: } \\
34.7 \text { months } \pm 19.2 \\
\text { Min: } 3.0 \text { months } \\
\text { Max: } 71.5 \text { months }\end{array}$ & $\begin{array}{c}\text { Median: } 36.5 \text { months } \\
\text { Mean: } \\
36.1 \text { months } \pm 21.2 \\
\text { Min: } 3.0 \text { months } \\
\text { Max: } 71.5 \text { months }\end{array}$ & $\begin{array}{l}\text { Median: } 30.4 \text { months } \\
\text { Mean: } \\
34.2 \text { months } \pm 18.5 \\
\text { Min: } 3.5 \text { months } \\
\text { Max: } 69.0 \text { months }\end{array}$ & 0.473 \\
\hline
\end{tabular}

*Lack of appropriate consent or lack of samples, ${ }^{1}$ Data are in \% or median ( \pm standard deviation), CEA: CarcinoEmbryonic Antigen, CA19.9: Cancer antigen.

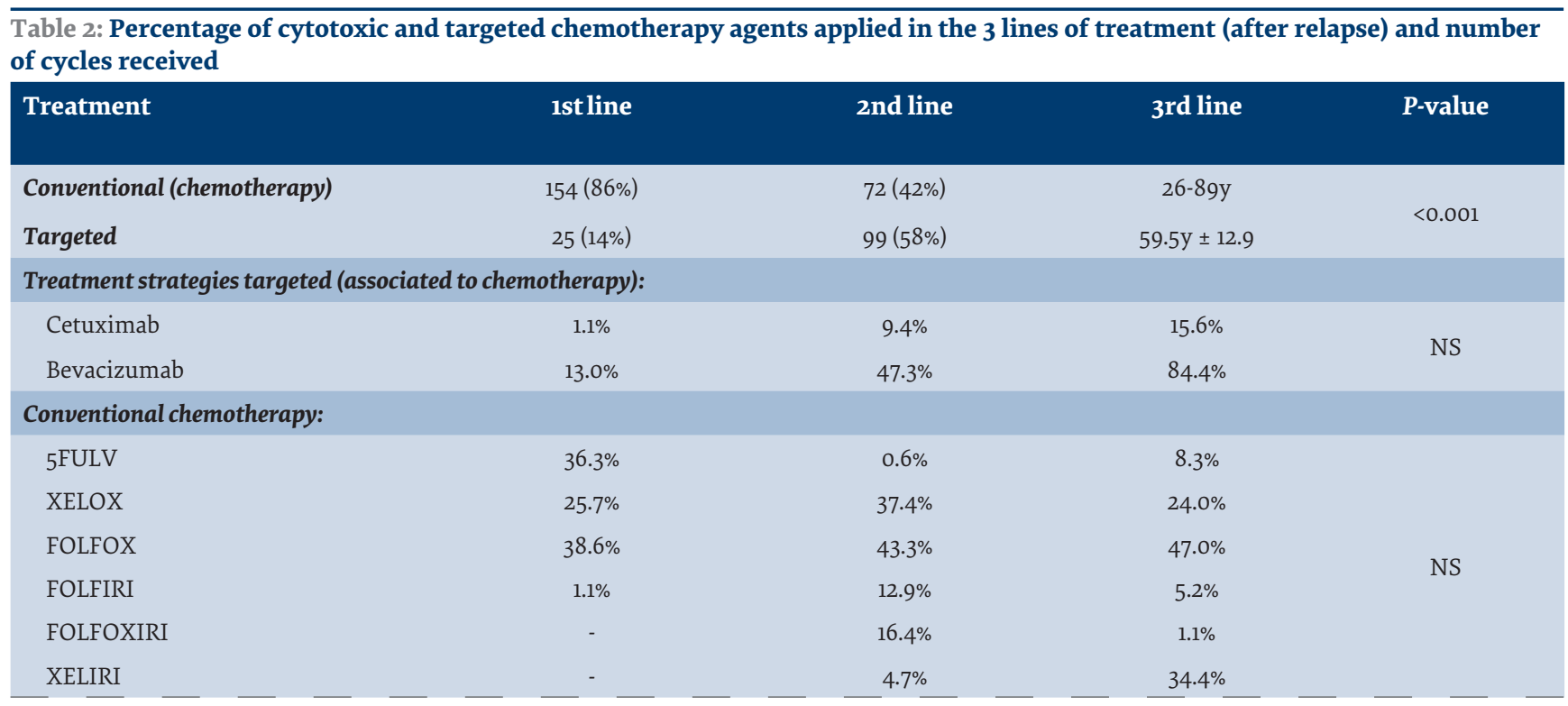




\begin{tabular}{|c|c|c|c|c|}
\hline Treatment & 1st line & 2nd line & 3rd line & P-value \\
\hline \multicolumn{5}{|l|}{ Cycles } \\
\hline$\leq 4$ cycles & $16.8 \%$ & $15.6 \%$ & $56.4 \%$ & \multirow{4}{*}{ NS } \\
\hline 5 - 6 cycles & $41.9 \%$ & $27.4 \%$ & - & \\
\hline 7 -8 cycles & $19.0 \%$ & $30.7 \%$ & - & \\
\hline$\geq 9$ cycles & $22.3 \%$ & $21.8 \%$ & - & \\
\hline
\end{tabular}

5FU/LV = Fluorouracil/Leucovorin, FOLFOX = Fluorouracil, Leucovorin, and Oxaliplatin; XELOX = Capecitabine and Oxaliplatin; FOLFIRI = Irinotecan, Fluorouracil, and Leucovorin, FOLFOXIRI = Fluorouracil, Leucovorin, Oxaliplatin and Irinotecan, XELIRI = Capecitabine and Irinotecan. NS = Non-significant.

gression of the disease (Table 3), with $17 \%$ in the cytotoxic group vs $16 \%$ in the targeted + cytotoxic group $(P>0.05)$; 57 vs $11 \%(P<0.05)$ and 18 vs $14 \%(P>0.05)$ from line 1 to 3 respectively; whereas the disease control rate was improved in the third line therapy (61\% in the cytotoxic group vs $56 \%$ in the targeted + cytotoxic group, but the difference was not statistically significant). In addition, the PD (or TTP) was higher in cytotoxic + targeted group in lines 1 and 2 (40 vs 44\% and 29 vs 46\%), but decreased in line 3 ( 82 vs $67 \%$ ); however, the difference was not statistically significant with a higher cost (min. = \$127 184; max. $=\$ 304086$ )

The median PFS was 35 months in the first line cytotoxic group and 31 months in the cytotoxic + targeted group, $(P=0.01)$ whereas in the second and third line, it was 37 months vs 34.8 months $(P=0.99)$ and 27 months vs 34.2 months $(P=0.37)$ respectively (Table 3$)$. KRAS gene status was evaluated in 120 tumors; 58 samples were excluded because of lack of samples or inappropriate consent. An activating KRAS mutation was found in 27 tumors $(15.1 \%)$, nine patients $(33.3 \%)$ with KRAS mutation were still alive whereas in wild KRAS patients $(\mathrm{n}=93$, $52 \%), 39(41.9 \%)$ stayed alive $(P=0.001)$. The response rate was significantly lower in those with KRAS mutations than in those with wild-type KRAS tumors (6\% vs $28 \%$, $P=0.01)$

The number of metastases at the time of diagnoses and recurrence greatly influenced the response to treatment and consequently the rate of survival. Eightysix $(48 \%)$ patients had $\geq 2$ metastases, of whom $32(37.2 \%)$ responded to treatment, whereas for patients having only one metastatic site ( $n=92,52 \%$ ), the response to treatment was 54.3\%. $(P=0.044)$. Overall response rate was inferior in patients having $\geq 2$ metastases than in patients with only one metastasis $(18 \%$ vs $47 \%, P=0.004)$.

\section{Survival results}

The Kaplan-Meier survival curve of the metastatic colorectal cancer cohort is displayed in Figure 1. The median of survival in the whole population was 20.8 months (625 days) (CI 95\% = 10.7-30.9 months); 49.7\% were still alive at the end of the study. Survival analysis revealed that the addition of targeted therapy failed to improve mCRC patients' survival $(P<0.002)$.

\section{Adjusted survival analysis}

In the multivariate model adjusted for age, number of metastases and toxicities, only toxicities were found

Table 3: Tumour assessment responses and effectiveness of treatment, all protocols combined

\begin{tabular}{|c|c|c|c|c|c|c|c|c|c|}
\hline \multirow[t]{2}{*}{ Outcomes } & \multicolumn{2}{|c|}{ 1st line } & \multirow[t]{2}{*}{${ }^{*} \boldsymbol{P}$} & \multicolumn{2}{|c|}{ 2nd line } & \multirow[t]{2}{*}{${ }^{*} \boldsymbol{P}$} & \multicolumn{2}{|c|}{ 3rd line } & \multirow[t]{2}{*}{${ }^{*} \mathbf{P}$} \\
\hline & $\begin{array}{c}\text { Cytotoxic } \\
(\mathrm{N}=153)\end{array}$ & $\begin{array}{c}\text { Targeted } \\
+ \\
\text { cytotoxic } \\
(\mathbf{N}=25)\end{array}$ & & $\begin{array}{l}\text { Cytotoxic. } \\
\qquad(\mathrm{N}=71)\end{array}$ & $\begin{array}{c}\text { Targeted + } \\
\text { cytotoxic } \\
(\mathrm{N}=99)\end{array}$ & & $\begin{array}{c}\text { Cytotoxic } \\
(\mathbf{N}=11)\end{array}$ & $\begin{array}{c}\text { Targeted+ } \\
\text { cytotoxic } \\
(\mathbf{N}=\mathbf{8 8})\end{array}$ & \\
\hline \multicolumn{10}{|l|}{ Tumour response rate } \\
\hline Complete response & $6(4 \%)$ & $1(4 \%)$ & & $18(25 \%)$ & $7(7 \%)$ & & $1(9 \%)$ & $6(7 \%)$ & \\
\hline Partial response & $20(13 \%)$ & $3(12 \%)$ & & $12(17 \%)$ & $4(4 \%)$ & & $1(9 \%)$ & $6(7 \%)$ & \\
\hline Stability & $67(44 \%)$ & $10(40 \%)$ & & $21(29 \%)$ & $42(43 \%)$ & & $\mathrm{o}(0 \%)$ & $17(19 \%)$ & \\
\hline Progression & $60(40 \%)$ & $11(44 \%)$ & 20.975 & $21(29 \%)$ & $46(46 \%)$ & 0.000 & $9(82 \%)$ & $59(67 \%)$ & 0.5 \\
\hline Disease control rate (\%) & 61 & 56 & & 71 & 54 & & 18 & 33 & \\
\hline Response rate (\%) & 17 & 16 & & 57 & 11 & & 18 & 14 & \\
\hline Progression of the disease (\%) & 40 & 44 & & 29 & 46 & & 82 & 67 & \\
\hline $\begin{array}{l}\text { Progression free survival } \\
\text { (months) }{ }^{* *}\end{array}$ & 35 & 31 & 0.01 & 37 & 34.8 & 0.99 & 27 & 34.2 & 0.37 \\
\hline
\end{tabular}




\begin{tabular}{|c|c|c|c|c|c|c|c|c|}
\hline \multirow{3}{*}{$\begin{array}{l}\text { Variable } \\
\text { (N patients) } \\
\text { Arm A (48) vs Arm B* (131) }\end{array}$} & \multicolumn{4}{|c|}{ Unadjusted } & \multicolumn{4}{|c|}{ Adjusted $^{* *}$} \\
\hline & \multirow{2}{*}{$\begin{array}{l}\text { HR } \\
0.50\end{array}$} & \multicolumn{2}{|c|}{$95 \% \mathrm{CI}$} & \multirow{2}{*}{$\begin{array}{c}\text { P-value } \\
0.014\end{array}$} & \multirow{2}{*}{$\begin{array}{l}\text { HR } \\
0.76\end{array}$} & \multicolumn{2}{|c|}{$95 \% \mathrm{CI}$} & \multirow{2}{*}{$\begin{array}{c}\text { P-value } \\
0.379\end{array}$} \\
\hline & & 0.29 & 0.87 & & & 0.41 & 1.40 & \\
\hline Age at diagnosis & 1.0 & 0.98 & 1.01 & 0.852 & 1.00 & 0.99 & 1.02 & 0.785 \\
\hline Males (103) vs Females (75) & 1.49 & 0.96 & 2.31 & 0.075 & - & - & - & - \\
\hline \multicolumn{9}{|l|}{ Markers (reference) Not $\uparrow(63)$} \\
\hline $\mathrm{CEA} \uparrow(54)$ & 1.77 & 1.00 & 3.15 & 0.052 & - & - & - & - \\
\hline Ca19.9个(11) & 1.71 & 0.69 & 4.23 & 0.243 & - & - & - & - \\
\hline Both $\uparrow(50)$ & 2.95 & 1.72 & 5.04 & 0.000 & - & - & - & - \\
\hline \multicolumn{9}{|c|}{ Toxicities (reference) Grade 2 (24) } \\
\hline Grade 3 (110) & 12.79 & 1.77 & 92.68 & 0.012 & 11.50 & 1.58 & 83.79 & 0.016 \\
\hline Grade 4 (44) & 33.16 & 4.55 & 241.66 & 0.001 & 28.71 & 3.91 & 210.60 & 0.001 \\
\hline $\begin{array}{l}\geq 2 \text { metastases ( } 86) \text { vs } \\
1 \text { metastases }(92)\end{array}$ & 1.86 & 1.21 & 2.85 & 0.004 & 1.46 & 0.91 & 2.34 & 0.117 \\
\hline $\begin{array}{l}\text { Liver metastases ( } 45 \text { ) vs } \\
\text { No liver metastases (133) }\end{array}$ & 0.57 & 0.33 & 0.98 & 0.041 & - & - & - & - \\
\hline
\end{tabular}

${ }^{*}$ Arm A cytotoxic agents; Arm B cytotoxic agents and targeted therapy.

${ }^{* *}$ Multivariate cox regression with a forward stepwise entry.

\begin{tabular}{|c|c|c|c|c|}
\hline Variable & Categories & Adjusted OR & $95 \% \mathrm{CI}$ & P-value* \\
\hline First-line treatment & $\begin{array}{l}\text { Cytotoxic vs targeted } \\
+ \text { cytotoxic }\end{array}$ & 1.13 & $0.46-2.78$ & 0.790 \\
\hline Number of metastases & $\geq 2$ vs 1 & 1.87 & $0.94-3.72$ & 0.074 \\
\hline \multirow[t]{3}{*}{ Toxicities } & Grade 2 (reference) & & & \\
\hline & Grade 3 & 2.81 & $0.87-9.12$ & 0.085 \\
\hline & Grade 4 & 4.48 & $1.26-15.92$ & 0.021 \\
\hline \multirow[t]{4}{*}{ Markers } & No $\uparrow$ (reference) & & & \\
\hline & $\mathrm{CEA} \uparrow$ & 2.46 & $1.08-5.60$ & 0.033 \\
\hline & Ca19.9个 & 1.89 & $0.48-7.36$ & 0.362 \\
\hline & Both $\uparrow$ & 1.67 & $0.69-4.07$ & 0.256 \\
\hline
\end{tabular}

${ }^{*}$ Multiple logistic regression (variables associated to progression with a P-value $<0.2$ in the bivariate analysis were entered in the model).

Table 6: Independent predictors of progression (RECIST 2) after the second-line of treatment $(\mathrm{N}=170)$

\begin{tabular}{|c|c|c|c|c|}
\hline Variable & Categories & Adjusted OR & $95 \%$ CI & P-value* \\
\hline Second-line treatment & $\begin{array}{l}\text { Cytotoxic vs targeted } \\
+ \text { cytotoxic }\end{array}$ & 0.55 & $0.26-1.17$ & 0.120 \\
\hline Number of metastases & $\geq 2$ vs 1 & 2.21 & $1.03-4.74$ & 0.041 \\
\hline \multirow[t]{3}{*}{ Toxicities } & Grade 2 (reference) & & & \\
\hline & Grade 3 & 3.43 & $0.70-16.70$ & 0.128 \\
\hline & Grade 4 & 10.14 & $1.92-53.46$ & 0.006 \\
\hline \multirow[t]{4}{*}{ Markers } & No $\uparrow$ (reference) & & & \\
\hline & $\mathrm{CEA} \uparrow$ & 1.40 & $0.55-3.60$ & 0.480 \\
\hline & Ca19.9 & 6.81 & $1.52-30.57$ & 0.012 \\
\hline & Both $\uparrow$ & 3.35 & $1.27-8.84$ & 0.014 \\
\hline
\end{tabular}

${ }^{*}$ Multiple logistic regression (variables associated to progression with a P-value $<0.2$ in the bivariate analysis were entered in the model). 


\begin{tabular}{|c|c|c|c|c|}
\hline Variable & Categories & Adjusted OR & $95 \% \mathrm{CI}$ & P-value* \\
\hline Third-line treatment & $\begin{array}{l}\text { Cytotoxic vs targeted } \\
+ \text { cytotoxic }\end{array}$ & 4.02 & $0.45-36.11$ & 0.214 \\
\hline Number of metastases & $\geq 2$ vs 1 & 1.09 & $0.32-1.74$ & 0.895 \\
\hline \multirow[t]{3}{*}{ Toxicities } & Grade 2 (reference) & & & \\
\hline & Grade 3 & - & - & - \\
\hline & Grade 4 & - & - & - \\
\hline \multirow[t]{4}{*}{ Markers } & No $\uparrow$ (reference) & & & \\
\hline & $\mathrm{CEA} \uparrow$ & 0.39 & $0.09-1.74$ & 0.217 \\
\hline & CA19.9个 & 1.91 & $0.15-24.96$ & 0.621 \\
\hline & Both $\uparrow$ & 1.01 & $0.19-5.30$ & 0.991 \\
\hline
\end{tabular}

${ }^{*}$ Multiple logistic regression (variables associated to progression with a P-value $<0.2$ in the bivariate analysis were entered in the model).

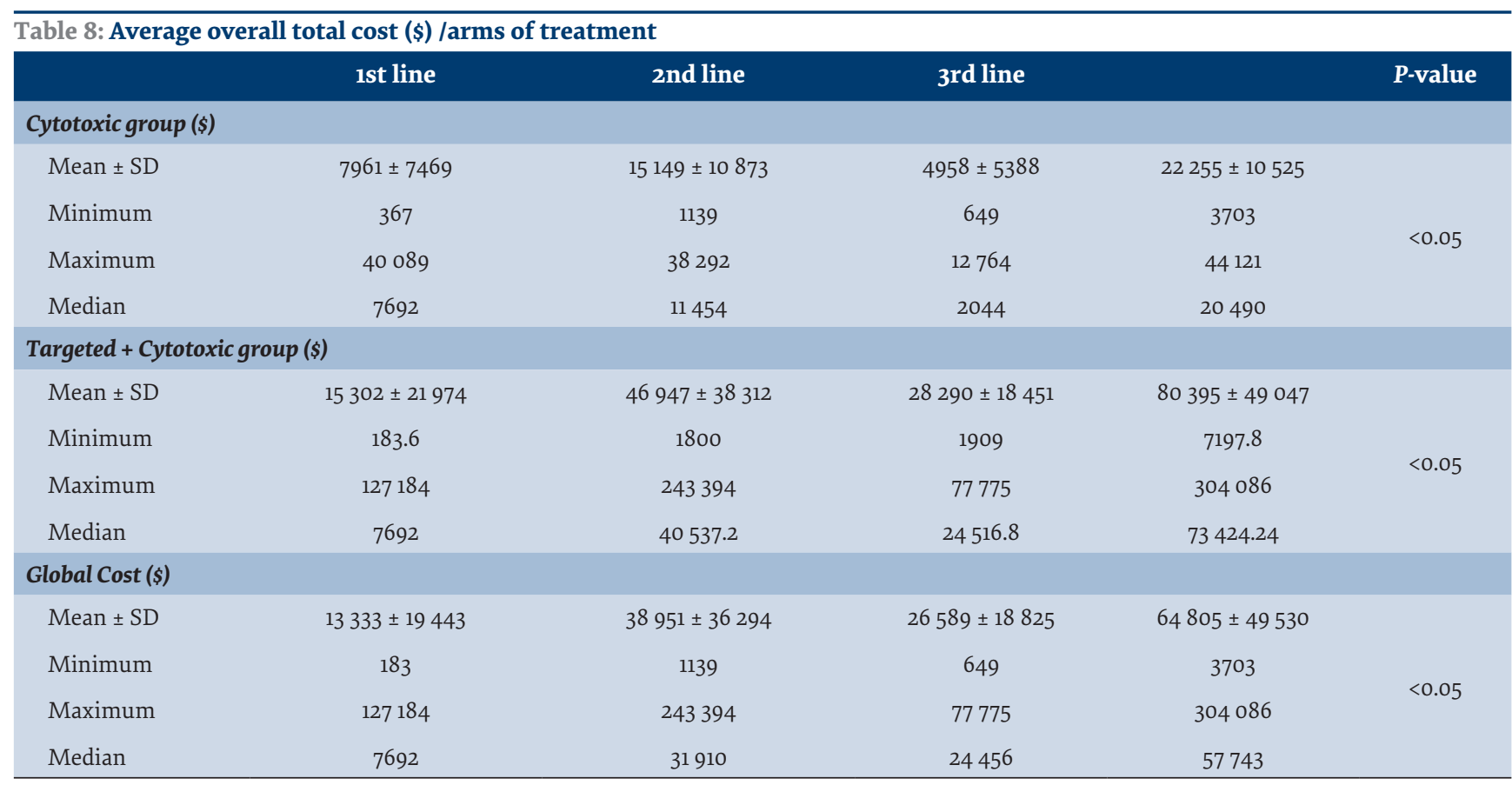

\begin{tabular}{|c|c|c|c|c|}
\hline Drug & Administration & Price/injection & Cost/dose & Cost/cycle (2 weeks) \\
\hline Bevacizumab & $5 \mathrm{mg} / \mathrm{kg} / \mathrm{d} / 2$ weeks & $\begin{array}{c}100 \mathrm{mg}=\$ 718 \\
400 \mathrm{mg}=\$ 2443\end{array}$ & $\$ 2443$ & $\$ 7329$ \\
\hline Cetuximab & $\begin{array}{c}400 \mathrm{mg} / \mathrm{m} 2 \\
\text { (Loading dose) } \\
250 \mathrm{mg} / \mathrm{m} 2 \\
\text { (Maintenance dose) }\end{array}$ & $\begin{array}{c}5 \mathrm{mg} / \mathrm{ml}(20 \mathrm{ml})=\$ 351 \\
5 \mathrm{mg} / \mathrm{ml}(100 \mathrm{ml})=\$ 1467\end{array}$ & $\$ 2520$ & $\$ 3573$ \\
\hline
\end{tabular}

\begin{tabular}{|c|c|c|c|}
\hline $\begin{array}{c}\text { XELOX } \\
\text { (Cycle of 21d) }\end{array}$ & $\begin{array}{c}\text { FOLFOX-6 } \\
\text { (Cycle of 14d) }\end{array}$ & $\begin{array}{c}\text { FOLFOX-4 } \\
\text { (Cycle of 14d) }\end{array}$ & $\begin{array}{c}\text { FOLFIRI } \\
\text { (Cycle of 14d) }\end{array}$ \\
\hline $\begin{array}{l}\text { Oxaliplatin } \$ 1481 \\
\text { Capecitabine } \$ 428\end{array}$ & $\begin{array}{c}\text { Oxaliplatin } \$ 1139 \\
\text { Leucovorin } \$ 76 \\
\text { 5-FU (Bolus) \$2.50 } \\
\text { 5-FU (Perfusion) } \$ 14.90\end{array}$ & $\begin{array}{c}\text { Oxaliplatin } \$ 969 \\
\text { Leucovorin } \$ 76 \\
\text { 5-FU (Bolus) \$2.50 } \\
\text { 5-FU (Perfusion) \$3.71 }\end{array}$ & $\begin{array}{c}\text { Irinotecan } \$ 518 \\
\text { Leucovorin } \$ 76 \\
\text { 5-FU (Bolus) \$2.50 } \\
\text { 5-FU (Perfusion) } \$ 3.71\end{array}$ \\
\hline Total $=\$ 1909$ & Total $=\$ 1233$ & Total $=\$ 1051$ & Total $=\$ 600$ \\
\hline
\end{tabular}


Figure 1: Kaplan-Meier curve for OS in the study cohort $(\mathrm{N}=179)$ of $\mathrm{mCRC}$ patients

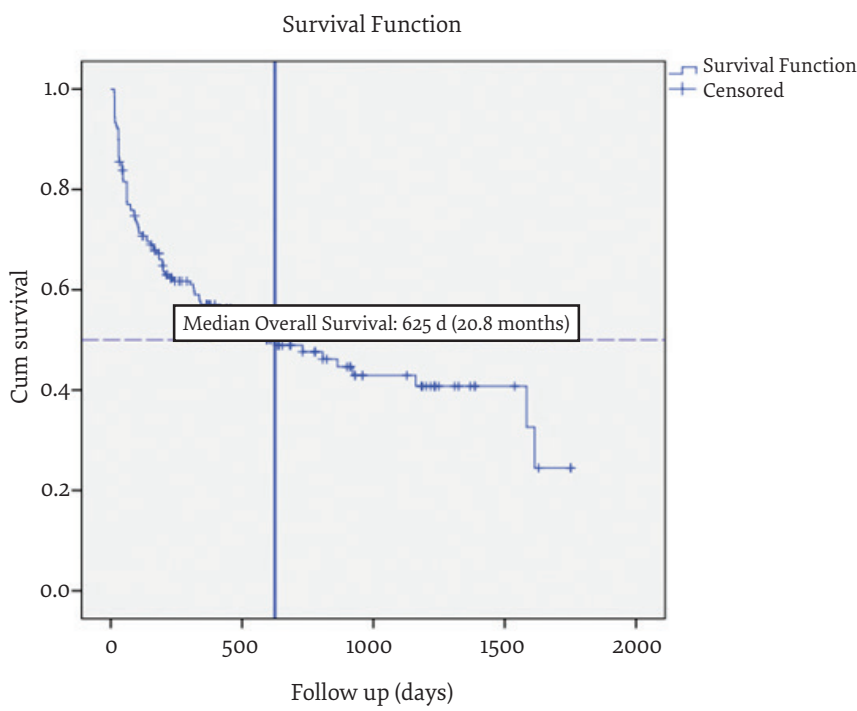

to be an independent predictor of the time to death (Table 4) (grade 3 vs grade $2 ; \mathrm{HR}=11.50$. 95\% $\mathrm{CI}=[1.578$ 83.79]; $P=0.016$; grade 4 vs grade $2 ; H R=28.71 ; 95 \%$
$C I=[3.91-210.59] ; P=0.001)$. No difference was observed when comparing cytotoxic group patients (Group A) to cytotoxic-targeted group patients (Group B) $(P=0.379)$. In the sensitivity analysis between the three lines of treatment, a slightly positive result was observed for Group B vs Group A for time to death in lines two and three, but the difference was not statistically significant. Thus, survival analysis revealed that the addition of targeted therapy failed to improve mCRC patients' survival (Figure 2).

\section{Treatment and RECIST}

In the multivariate models adjusted for the number of metastases ( $\geq 2$ metastases vs 1 metastasis), toxicities (grades 2 and 4) and markers (increase in CEA and/or CA19.9), the association between treatment (cytotoxic or cytotoxic+targeted) and RECIST (progression vs no progression) was not statistically significant in all three lines of therapy (Table 5, Table 6, Table 7). We did not include "KRAS mutations" in the multivariate models because of the high number of missing values (58 missing).

\section{Colorectal cancer treatment costs}

The corresponding costs of cytotoxic and targeted drugs are shown in Table 8, Table 9a and Table 9b. The corres-

Figure 2: Cox Survival curves showing the differences on survival between the 2 groups and the 3 lines of therapy respectively (after adjustment for age, number of metastases and toxicities). In the sensitivity analysis between the 3 lines of treatment, a slight advantage of the cytotoxic + targeted group versus cytotoxic on time to death was shown in lines 2 and 3 although not statistically significant.
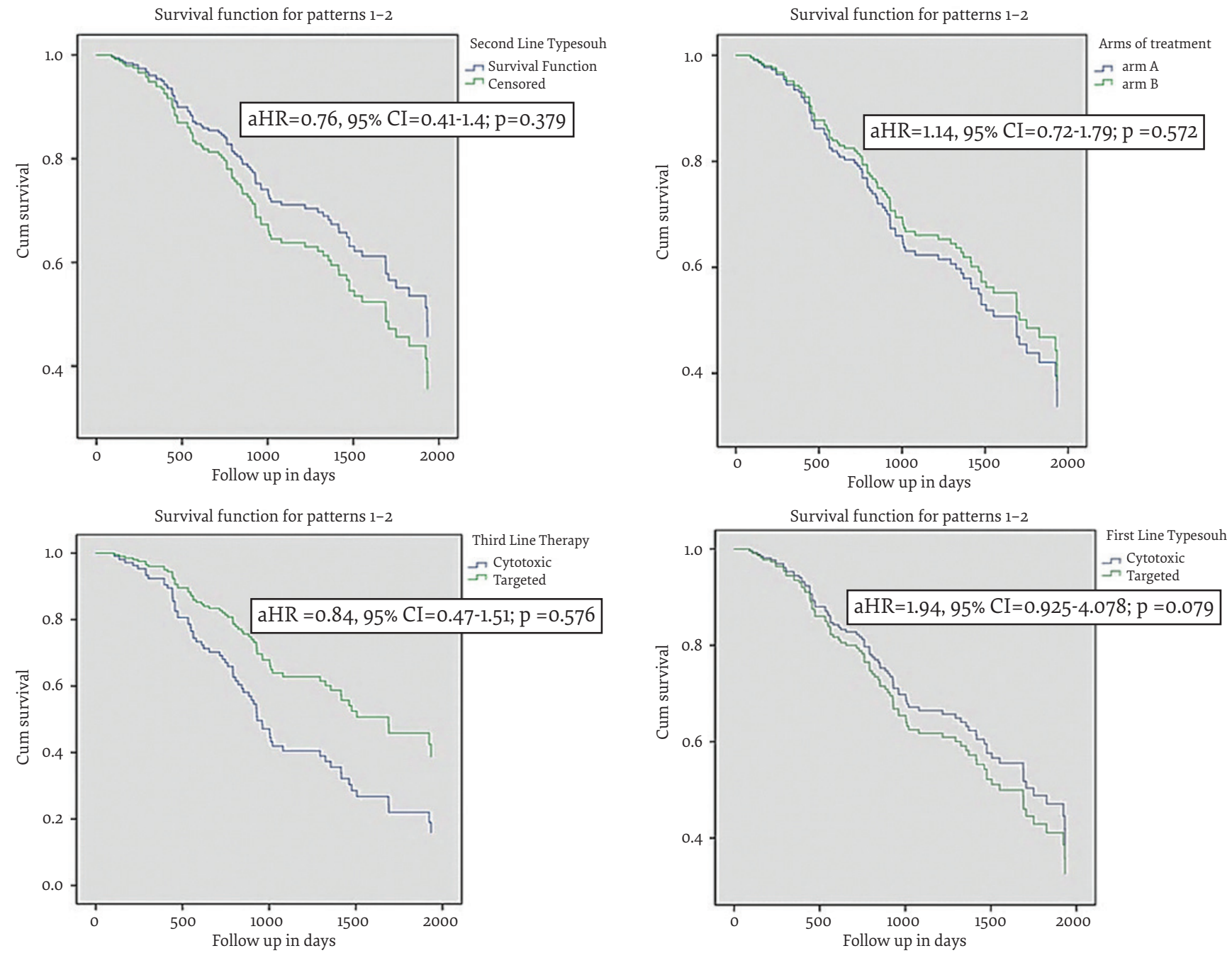
Figure 3: "Box-Plot" diagram of the total global costs in patients with mCRC in our study

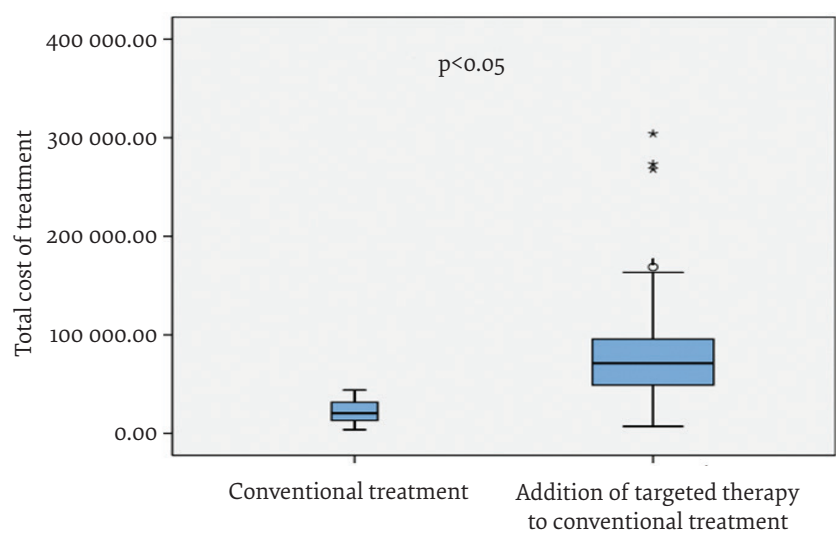

ponding total costs for all lines combined are as follows: cytotoxic group $=\$ 22255(P<0.05)$, cytotoxic associated to targeted therapy $=\$ 80395(P=0.001)$ and global total cost $=\$ 64805(P=0.000)$, respectively $(\min .=\$ 127184 ;$ max. $=\$ 304$ 086). As shown in the Box-Plot diagram (Figure 3), the addition of targeted therapy to conventional treatment demonstrates an approximate fourfold increase in expense.

\section{Discussion}

According to the current available literature, this is the first study to estimate the real costs (cost of the disease) of chemotherapy associated to biotherapy for metastatic colorectal cancerfrom the perspective of the Lebanese public health system, using accurate cost-related data. Few studies have evaluated general costs of specific treatments for cancer in high-income countries (19,23-25). Most studies on treatment costs of metastatic colorectal cancer compared the costs of XELOX with FOLFOX-6 regimens, since it is suggested that both therapies are similar in terms of efficacy and safety. A cost-minimization study conducted in Australia has demonstrated that the use of XELOX in first-line and second-line treatment for metastatic colorectal cancer reduced the average cost by $\$ 9110$ and $\$ 7113$ respectively, as compared with mFOLFOX (26). From the French health insurance perspective, when compared with mFOLFOX-6, XELOX resulted in lower costs related to drug acquisition and shorter hospitalizations per patient $(23,24)$.

With the exception of 5-FU and irinotecan, these drugs are very expensive and the cost implications of these promising medications are the subject of significant debate (8-10,26-28). There are limited data in the published literature regarding the cost effectiveness of treatments for patients with metastatic colorectal cancer. Hillner used data from the multicenter study NCCTG 9741 to compare treatment with FOLFIRI to FOLFOX and found that the 4.4 month median survival benefit of the FOLFOX arm was accompanied by an incremental cost of \$29 953, resulting in an incremental cost effectiveness ratio (ICER) of $\$ 80410$ per life year gained $(11,29)$. Starling examined the role of cetuximab and irinotecan compared to best supportive care from the perspective of the United Kingdom National Health Service and found an ICER of GBP£42 975 per life year gained (17,21). To our knowledge, there has not been a comprehensive cost effectiveness analysis that includes multiple lines of therapy.

Despite recent advances in early detection and therapeutic intervention, colorectal cancer remains one of the most deadly cancers in Lebanon. While surgical removal leads to high cure rates of localized disease, metastatic colorectal cancer is typically associated with a poor prognosis with the majority of patients dying within two years from diagnosis, resulting in a five-year survival rate of only $12.8 \%(13-15,19,23,30)$. Therapeutic options currently available rely on three cytotoxic chemotherapies, fluoropyrimidine (5-FU, capecitabine) $(16,24,25,27,31-32)$, oxaliplatin, and irinotecan (28,33), and recently on the monoclonal antibodies cetuximab (second-line setting) or bevacizumab (first-line treatments and after progression) depending on the KRAS mutation $(26,29,30,34-36)$.

The choice of initial therapy should be tailored to individual needs of the patients, to toxicity profiles of each regimen and to the potential impact of initial therapy on later phases of the treatment. The central goal is to optimize survival, time without toxicity from chemotherapy, and quality of life. The National Cancer treatment guidelines, published by the Lebanese Ministry of Health, define the most recent protocols to be adopted taking in consideration of ASCO (American Society of Clinical Oncology) and ESMO (European Society for Medical Oncology) results. The intensification of the treatment (tri-therapy, with or without monoclonal antibodies) is reserved for resectable colorectal cancer patients and the adjunction of bevacizumab was validated in Lebanon, since 2006 and after 2012, beyond progression with a significant improvement in overall survival. However, the drug's high cost and nonavailability (difficulties in reimbursement), make it indicated only in aggressive disease as first-line setting, and is mostly used in second/third-line treatment as maintenance therapy to prevent relapses.

Although patients $\geq 65$ years of age represent the majority of patients with metastatic colorectal cancer $(35,37)$, the mean age at diagnosis in this study was 60.5 years, which might be due to the young age of the cohort (range 26-89 years). Median overall survival was reported in the study as 20.8 months, which was inferior to that reported by Saltz et al. (2008), and Crystal, Tree and Cremolini et al. (2015), where overall survival after the administration of targeted therapy was significantly increased (from 24 months to 30 months) $(22,38)$.

Survival increases as patients with metastatic colorectal cancer are exposed to all available agents, but this benefit comes at high cost, which exceeds commonly accepted cost-effectiveness thresholds (24). Furthermore, our estimates only include drug costs, representing a conservative estimate of total treatment expense. Patients 
who are treated with $5 \mathrm{FU} / \mathrm{LV}$, oxaliplatin, irinotecan or with monoclonal antibodies have longer survival compared to $5 \mathrm{FU} / \mathrm{LV}$ alone but higher costs. These results are similar to an analysis of salvage chemotherapy in platinum refractory ovarian cancer, which found that second-line monotherapy came at an ICER of $\$ 57000 /$ DLY, but the benefits of second-line doublet therapy and third-line monotherapy came at unacceptably high incremental cost (25). Whether the benefits are worth the costs clearly depends on the stakeholder; patients with advanced cancer may perceive greater value than healthy patients, policymakers, insurers, and physicians $(8,9,27,28)$.

This study comprehensively analyzed clinical effectiveness and associated medical costs with the use of chemotherapy alone or chemotherapy + targeted agents in patients with metastatic colorectal cancer. We found that the health care costs of colorectal cancer treatment increased significantly with advanced disease, especially for the second-line setting, which is most likely attributable to the use of new drug regimens and protocols (Table 4). Our goal was not to compare "competing" regimens such as FOLFOX and FOLFIRI, which are both acceptable first-line treatment strategies (27), but instead to study the impact of sequential progress (new chemotherapy and antibodies) on the overall cost of managing metastatic colorectal cancer. We found that similar treatment sequences had similar life expectancies, suggesting that the costs are not affected by the sequence in which the drugs are used, but rather the effectiveness of the overall treatment strategy.

At the present time, patients with metastatic colorectal cancer are typically treated with a first-line chemotherapy regimen that is continued until documented disease recurrence. Upon progression, patients are switched to a regimen with demonstrated activity on refractory disease. This pattern of treatment continues until patients show progression of their disease and then are switched to non-cross resistant therapy. The last therapies can be changed until all five classes of active agents have been tried.

In patients who were previously treated with the same chemotherapy regimen (first-line included), the addition of targeted therapy to this regimen allowed a response rate of $14 \%$ (vs $18 \%$ ), a disease control rate of $33 \%$ (vs 18\%) and a stabilization of $19 \%$ (vs 0\%), suggesting that molecular therapy may circumvent resistance to conventional chemotherapy by allowing a more efficient delivery of chemotherapeutic agents. Tumor vasculature is structurally and functionally abnormal, which results in a heterogeneity in tumor blood flow with interstitial hypertension, hypoxia and acidosis. Hypoxia could therefore make tumour cells resistant to several cytotoxic drugs by interfering with the penetration of these drugs throughout the tumour $(34,39)$. This phenomenon was not observed when cetuximab (anti-EGFR antibody) was added to bevacizumab and chemotherapy; on the contrary, it had a possible deleterious effect (31-33,40-
44). This study also found that patients, specifically the elderly with more than one metastatic site, had higher costs while patients with only one progression or only one line of therapy had lower costs.

Costs connected with metastatic colorectal cancer, primarily those associated with chemotherapy and targeted medications, represent a significant percentage share of total costs. The cost of chemotherapy rose from $6.9 \%$ of total costs in 2004 to $8.1 \%$ in 2008 , and the cost of targeted medications rose from $4.8 \%$ in 2004 to $9.4 \%$ in 2008. Costs connected with metastatic colorectal cancer were $\$ 9978$ per month. Ferro et al. determined that there was growth in the total costs of metastatic colorectal cancer treatment from 1996 onwards, specifically due to increased choice among possible medications, and targeted medications have substantially increased the cost of treating metastatic colorectal cancer (37,45). Most studies that provide estimates of the long-term cost of colorectal cancer were conducted in the United States of America (6-9,46-48), but to our knowledge, there are no such studies in Lebanon and in the Middle East in general.

It was also noticed that patients with comprehensive insurance (health maintenance organizations and indemnity insurance plans) had lower costs than noninsured participants. The oncological treatment for metastatic disease in 2014 is less toxic and more effective but more expensive (because of the use of monoclonal antibodies). The addition of multiple lines of protocols, mainly targeted and biological agents, to the backbone of chemotherapy, allows better overall survival and PFS (49).

\section{Limitations}

The sample size in this study is too small to make any definitive recommendations or suggest a change in practice guidelines, therefore collaboration with other cancer centers across the country and generate more data could be subjected to pre-defined rigorous statistical analysis. In addition, official Lebanese tariffs for the year 2013 were the only ones considered. Concerning the screening, there was no National colorectal survival screening strategy or education awareness programme; the screening with fecal occult blood testing is rarely practiced and gastroenterologists recommend and perform screening colonoscopy on an erratic and opportunistic basis.

Many other variables (not found to be significantly associated to death or RECIST in our study such as mutations, histology, differentiation, treatment duration, and types of metastases) may influence time to death or disease progression, but we could not add them in the analysis because of large number of missing values. Differing organization of health systems and different practice patterns and settings made the transferability of country specific results not always possible, so further studies specific to Lebanon are needed. 
All drugs are given intravenously in fixed vial sizes, and the total wastage of all drugs that remained in vials at the end of the infusion for each patient was not assumed. Our analysis did not consider indirect costs such as work loss resulting from chemotherapy, tax payer's perspective or direct costs such as transportation to the hospital.

Despite the limitations of this cohort study, the results are useful in presenting the pattern of care of patients with colorectal cancer in a real-life perspective. This approach may be complementary to results from clinical trials since it is more representative of routine clinical practices. This type of study may also represent useful information within the scope of medical-decision making.

\section{Conclusion}

This study is, to our knowledge, the first to investigate the real costs of healthcare in patients with a diagnosis of $\mathrm{mCRC}$ and receiving systemic therapy (chemotherapy or biotherapy), considering both costs per treatment cycle and total costs per patient based on the Lebanese perspective of the situation. Moreover, it should be standard practice to discuss the option of chemotherapy with patients while outlining the potential toxicities. Analysis of the cost-effectiveness of treatments, including financial and physical costs of toxicities, is becoming increasingly important and strategies to optimize this are vital. We need to balance efficacy of treatment, costs involved with the short- and long-terms toxicities to create a truly Lebanese standard of care for adjuvant colon cancer.

\section{Acknowledgements}

We thank the participating patients, their family members and researchers in this study. We are grateful to Mr Chayban Matar for the statistical analysis.

The results of this study were presented as poster/abstract form at the 22nd Lebanese Pharmaceutical Congress that took place 24 October 2014, Habtoor/Sin El Fil, Lebanon, and as an oral communication during the 25th Lebanese Pharmaceutical Congress, 17 November 2017, also at Habtoor/Sin El Fil, Lebanon.

Funding: Shiraz University of Medical Sciences, Shiraz, Islamic Republic of Iran.

Competing interests: None declared.

\section{Prise en charge des patients atteints d'un cancer colorectal métastatique dans les hôpitaux libanais et coût direct associé : étude de cohorte multicentrique \\ Résumé}

Contexte : Pour le cancer colorectal métastatique, une série de nouveaux traitements sont apparus durant la dernière décennie, mais leur utilisation dans la pratique clinique courante et leurs coûts ne sont pas bien documentés

Objectifs : La présente étude a évalué l'efficacité clinique de ce type de traitements sur les patients atteints de cancer colorectal métastatique dans les unités oncologiques libanaises et en a estimé les coûts.

Méthodes: Une étude de cohorte prospective a été menée sur des patients atteints de cancer colorectal métastatique au cours de la période 2008-2013. Le type de prise en charge médicale, la survie globale et les coûts totaux des traitements du diagnostic jusqu'au au décès ont été décrits. L'analyse des coûts a été réalisée sur la base des tarifs de 2013 en dollars US.

Résultats : Cent soixante-dix-neuf patients métastatiques ont été sélectionnés, dont 84,9\% présentaient une atteinte de type cancer colorectal métastatique. Le suivi moyen entre le diagnostic et le décès ou le dernier contact avec le patient était de 34,8 mois. Environ 49,7\% étaient encore en vie à la dernière date de suivi. Trois lignes de traitement représentaient $4,5 \%, 39,6 \%$ et $55,9 \%$ des cas, avec une durée moyenne de $14,5,11,4$ et 14,6 mois respectivement ; $73,2 \%$ des patients ont bénéficié d'un traitement ciblé. La survie globale médiane était de 20,8 mois. Le coût total moyen des médicaments s'élevait à USD 22256 chez les patients recevant un traitement standard seulement, alors que le coût passait à USD 80396 après l'ajout du traitement ciblé. Le coût total moyen global a été estimé à USD 64805 par patient (min. USD 3703 ; max. USD 304 086).

Conclusions : Le traitement ciblé associé au traitement standard est très répandu au Liban pour les maladies métastatiques et le coût médical associé est substantiel. Cette étude est la première à montrer l'efficacité clinique et les coûts d'un traitement ciblé chez des patients atteints de cancer colorectal métastatique. 


$$
\begin{aligned}
& \text { علاج مرضى سرطان القولون المستقيمي النقيلي في المستشفيات اللبنانية والتكلفة المباشرة المرتبطة بها: دراسة أترابية } \\
& \text { متعددة المر اكز مراجي }
\end{aligned}
$$

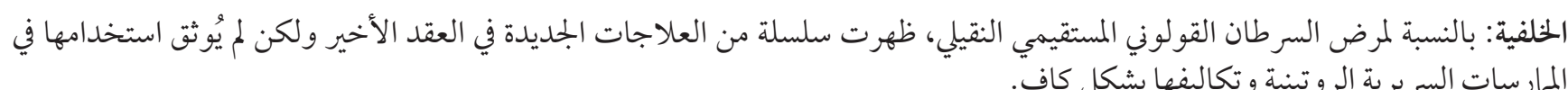

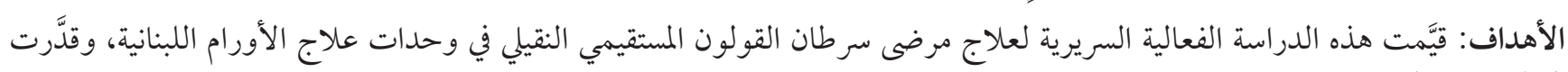
تكاليف هذا العلاج.

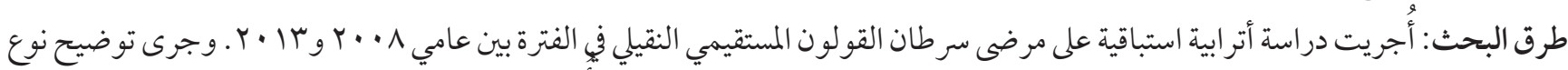

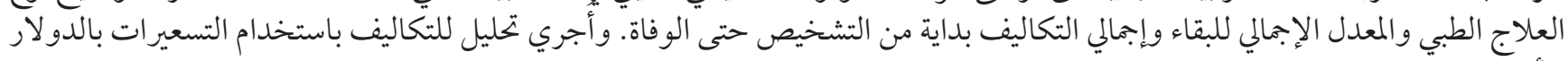

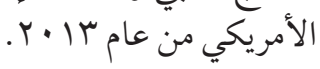

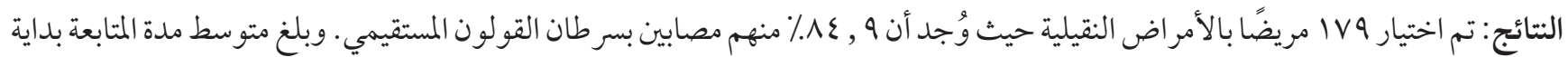

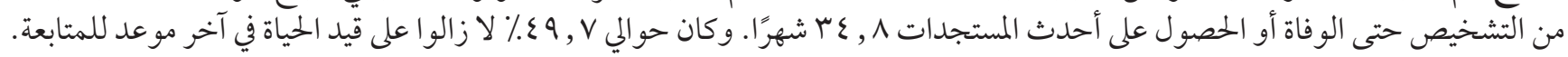

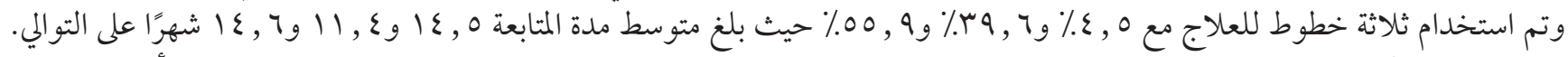

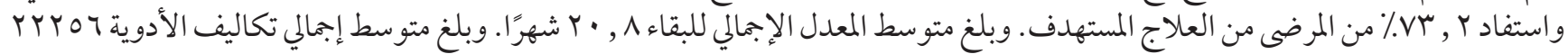

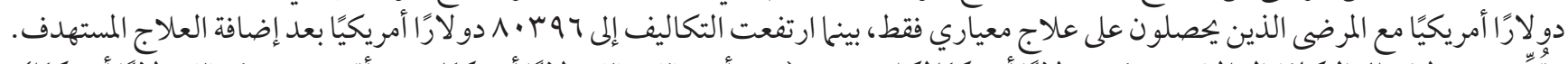

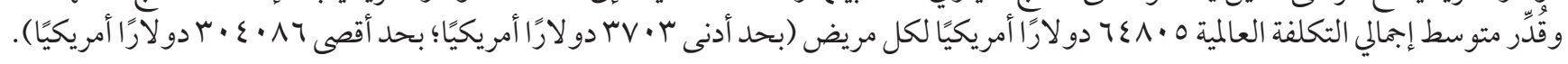

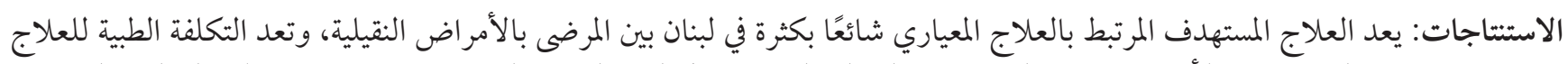

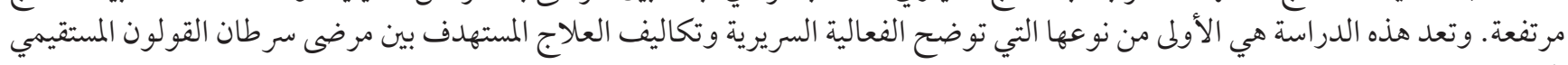

\section{References}

1. Nemer A, Hejase AJ, Hejase HJ. Colorectal Cancer: Exploring awareness in Lebanon. J Middle East North Afr Sci. 2016; 2(10):10-21. http://dx.doi.org/10.12816/0032694

2. Application LNCR. Epidemiology Surveillance program. Lebanese Ministry of Public Health http://www.moph.gov.lb

3. Haggar F, Boushey R. Colorectal Cancer Epidemiology: Incidence, Mortality, Survival, and Risk Factors. Clin Colon Rectal Surg. 2009; 22(04):191-7. http://dx.doi.org/10.1055/s-0029-1242458

4. Henaine A-M, Chahine G, Salameh C. Management of metastatic colorectal cancer: current treatments and new therapies. J Med Liban. 2015; 63(4):218-27. http://dx.doi.org/10.12816/0017971

5. El Zouhairi M, Charabaty A, Pishvaian M. Molecularly Targeted Therapy for mCRC: Proven treatments and promising new agents. Gastrointest Cancer Res. 2011; 4(1):15-21.

6. Rodriguez J. Combining chemotherapy and targeted therapies in metastatic colorectal cancer. World J Gastroenterol. 2007; 13(44):5867-76. http://dx.doi.org/10.3748/wjg.v13.i44.5867

7. Stein A, Glockzin G, Wienke A, Arnold A, Edelmann T, Hildebrandt B, et al. Treatment with bevacizumab and FOLFOXIRI in patients with advanced colorectal cancer: presentation of two novel trials (CHARTA and PERIMAX) and review of the literature. BMC Cancer. 2012; 12(1):356. http://dx.doi.org/10.1186/1471-2407-12-356

8. Van Cutsem E, Kohne CH, Lang I, Folprecht G, Nowacki MP, Cascinu S, et al. Cetuximab Plus Irinotecan, Fluorouracil, and Leucovorin as First-Line Treatment for Metastatic Colorectal Cancer: Updated Analysis of Overall Survival According to Tumor KRAS and BRAF Mutation Status. J Clin Oncol. 2011; 29(15):2011-9. http://dx.doi.org/10.1200/JCO.2010.33.5091

9. Saltz LB, Clarke S, Diaz-Rubio E, Scheithauer W, Figer A, Wong R, et al. Bevacizumab in combination with Oxaliplatin-based chemotherapy as first-line therapy in metastatic colorectal cancer: a randomized phase III study. J Clin Oncol. 2008; 26(12):2013-9. http://dx.doi.org/10.1200/JCO.2007.14.9930

10. Maughan TS, Adams RA, Smith CG, Meade AM, Seymour MT, Wilson RH, et al. Addition of Cetuximab to Oxaliplatin-based first-line combination chemotherapy for treatment of advanced colorectal cancer: results of the randomized phase 3 MRC COIN trials. Lancet. 2011; 377(9783):2103-14. http://dx.doi.org/10.1016/So140-6736(11)60613-2

11. Bencsikova B, Bortlicek Z, Halamkova J, Ostrizkova L, Kiss I, Melichar B, et al. Efficacy of Bevacizumab and chemotherapy in the first-line treatment of metastatic colorectal cancer: broadening KRAS-focused clinical view. BMC Gastroenterol. $2015 ; 15(1)$ :37. http://dx.doi.org/10.1186/s12876-015-0266-6 
12. Lin JK, Lin AJ, Lin CC, et al. The status of EGFR-associated genes could predict the outcome and tumor response of chemorefractory metastatic colorectal patients using cetuximab and chemotherapy. J Surg Oncol. 2011; 104:661-6.

13. Eisenhauer EA, Therasse P, Bogaerts J, Schwartz LH, Sargent D, Ford R, et al. New response evaluation criteria in solid tumors: revised RECIST guidelines (version 1.1). Eur J Cancer. 2009;45(2):228-47. http://dx.doi.org/10.1016/j.ejca.2008.10.026

14. Markowitz SD, Dawson DM, Willis J, Willson JKV. Focus on colon cancer. Cancer Cell. 2002; 1(3):233-6. http://dx.doi.org/10.1016/ S1535-6108(02)00053-3

15. Brand TM, Wheeler DL. KRAS mutant colorectal tumors: past and present. Small GTPases. 2012; 3(1):34-9. http://dx.doi. org/10.4161/sgtp.18751

16. Viale PH, Fung A, Zitella L. Advanced colorectal cancer: current treatment and nursing management with economic considerations. Clin J Oncol Nurs. 2005; 9(5):541-52. http://dx.doi.org/10.1188/05.CJON.541-552

17. Raikou M, McGuire A. Estimating medical care costs under conditions of censoring. J Health Econ. 2004; 23(3):443-70. http:// dx.doi.org/10.1016/j.jhealeco.2003.07.002

18. Young TA. Estimating mean total costs in the presence of censoring: a comparative assessment of methods. Pharmacoeconomics. 2005;23(12):1229-42. http://dx.doi.org/10.2165/00019053-200523120-00007

19. Jaffe CC. Measures of response: RECIST, WHO \& new alternatives. J Clin Oncol. 2006;24(26):3245-51. http://dx.doi.org/10.1200/ JCO.2006.06.5599

20. Monteil J, Mahmoudi N, Leobon S, Roudaut PY, et al. Chemotherapy Response Evaluation in mCRC with FDG PET/CT and CT scans. Anticancer Res. 2009; 29:2563-8.

21. Starling N, Tilden D, White J, Cunningham D. Cost-effectiveness analysis of cetuximab /irinotecan vs active/best supportive care for the treatment of metastatic colorectal cancer patients who have failed previous chemotherapy treatment. Br J Cancer. 2007; 96(2):206-12. http://dx.doi.org/10.1038/sj.bjc.6603561

22. Nishino M, Jackman D, Hatabu H, Yeap B, Cioffredi L-A, Yap JT, et al. New response evaluation criteria in solid tumors (RECIST). Guidelines for advanced non-small cell lung cancer: comparison with original RECIST and impact on assessment of tumor response to targeted therapy. AJR Am J Roentgenol. 2010; 195(3):W221-8. http://dx.doi.org/10.2214/AJR.09.3928

23. Perrocheau G, Bennouna J, Ducreux M, Hebbar M, Ychou M, Lledo G, et al. Cost-minimisation analysis in first-line treatM ment of metastatic colorectal cancer in France: XELOX versus FOLFOX-6. Oncology. 2010; 79(3-4):174-80. http://dx.doi. org/10.1159/000325999

24. Ungari A, Pereira L, Castro Perdoná G, Beltrame B, et al. Cost evaluation of metastatic colorectal cancer treatment in the Brazilian public healthcare system. J Interv Oncol. 2015; 4:2.

25. Lopatriello S, Amoroso D, Donati S, Alabiso O, Forti L, Fornasiero A, et al. The CAPCR study: direct medical costs in Italian metastatic colorectal cancer patients on first-line infusional 5-fluorouracil or oral capecitabine. Eur J Cancer. 2008; 44(17):2615-22. http://dx.doi.org/10.1016/j.ejca.2008.08.010

26. Schrag D. The price tag on progress-chemotherapy for colorectal cancer. N Engl J Med. 2004; 351(4):317-9. http://dx.doi. org/10.1056/NEJMp048143

27. Meropol NJ, Schulman KA. Perspectives on the Cost of Cancer Care. J Clin Oncol. 2007; 25(2):169-70. http://dx.doi.org/10.1200/ JCO.2006.09.9648

28. Meropol NJ, Schulman KA. Cost of cancer care: issues and implications. J Clin Oncol. 2007; 25(2):180-6. http://dx.doi.org/10.1200/ JCO.2006.09.6081

29. Hillner BE, Schrag D, Sargent DJ, Fuchs CS, Goldberg RM. Cost-effectiveness projections of oxaliplatin and infusional fluorouracil versus irinotecan and bolus fluorouracil in first-line therapy for metastatic colorectal carcinoma. Cancer. 2005; 104(9):1871-84. http://dx.doi.org/10.1002/cncr.21411

30. Knickelbein K, Zhang L. Mutant KRAS as a critical determinant of the therapeutic response of colorectal cancer. Genes Dis. 2015; 2(1):4-12. http://dx.doi.org/10.1016/j.gendis.2014.10.002

31. Meyerhardt JA, Mayer RJ. Systemic therapy for colorectal cancer. N Engl J Med. 2005; 352(5):476-87. http://dx.doi.org/10.1056/ NEJMra040958

32. Venook A. Critical evaluation of current treatments in metastatic CRC. Oncologist. 2005; 10(4):250-61. http://dx.doi.org/10.1634/ theoncologist.10-4-250

33. Sullivan KM, Kozuch PH. Impact of KRAS mutations on management of colorectal carcinoma. Patholog Res Int; $2011: 219309$. http://dx.doi.org/10.4061/2011/219309 PMID: 21437184

34. National Cancer Institute. Targeted cancer therapies. Bethesda, MD: National Cancer Institute; 2014.

35. Ghiringhelli F, Bichard D, Limat S, Lorgis V, Vincent J, Borg C, et al. Bevacizumab Efficacy in Metastatic Colorectal Cancer is Dependent on Primary Tumor Resection. Ann Surg Oncol. 2014; 21(5):1632-40. http://dx.doi.org/10.1245/s10434-013-3463-y

36. Sobrero A, Ackland S, Clarke S, Perez-Carrión R, Chiara S, Gapski J, et al. On behalf of the aviri Trial investigators. Phase IV study of bevacizumab in combination with infusional fluorouracil, leucovorin and irinotecan (FOLFIRI) in first-line metastatic colorectal cancer. Oncology. 2009; 77(2):113-9. http://dx.doi.org/10.1159/000229787 
37. Gouverneur A, Rouyer M, Grelaud A, Colombani F, Terrebonne E, Smith D, et al. Evaluation de la prise en charge médicamenteuse des sujets âgés présentant un CCRm : étude pilote observationnelle au CHU de Bordeaux, France. Rev Epidemiol Sante Publique. 2015;63:76. http://dx.doi.org/10.1016/j.respe.2015.03.088

38. Cremolini Ch, Loupakis F, Massi G, Zagonel V, et al. FOLFOXIRI plus bevacizumab vs FOLFIRI plus bevacizumab as first-line treatment for mCRC: Updated survival results of the phase III TRIAL by the GONO group. J Clin Oncol. 2015 ; Suppl 3, abstr 657

39. Lv Y, Zhao S, Han J, Zheng L, Yang Z, Zhao L. Hypoxia-inducible factor-1 $\alpha$ induces multidrug resistance protein in colon cancer. Onco Targets Ther. 2015; 8:1941-8. http://dx.doi.org/10.2147/OTT.S82835

40. Van Cutsem E, Kohne CH, Lang I, Folprecht G, Nowacki MP, Cascinu S, et al. Cetuximab plus irinotecan, fluorouracil, and leucovorin as first-line treatment for metastatic colorectal cancer: updated analysis of overall survival according to tumor KRAS and BRAF mutation status. J Clin Oncol. 2011; 29(15):2011-9. http://dx.doi.org/10.1200/JCO.2010.33.5091

41. Hecht JR, Mitchell E, Chidiac T, Scroggin C, Hagenstad C, Spigel D, et al. A randomized phase IIIB trial of chemotherapy, bevacizumab, and panitumumab compared with chemotherapy and bevacizumab alone for metastatic colorectal cancer. J Clin Oncol. 2009; 27(5):672-80. http://dx.doi.org/10.1200/JCO.2008.19.8135

42. Tol J, Koopman M, Cats A, Rodenburg CJ, Creemers GJM, Schrama JG, et al. Chemotherapy, bevacizumab, and cetuximab in metastatic colorectal cancer. N Engl J Med. 2009; 360(6):563-72. http://dx.doi.org/10.1056/NEJMoa0808268

43. Limat S, Bracco-Nolin CH, Legat-Fagnoni C, et al. Economic impact of simplified de Gramont regimen in first-line mCRC. Eur J Health Econ. 2006; 7(2):107-13.

44. Ferro SA, Myer BS, Wolff DA, Poniewierski MS, et al. Variation in the cost of medications for the treatment of colorectal cancer. Am J Manag Care. 2008; 14:717-25.

45. Temraz S, Mukherji D, Shamsiddine A. Sequencing of treatment in mCRC: where to fit the target? World J Gastroenterol. 2014; 20(8):1993-2004. http://dx.doi.org/10.3748/wjg.v20.i8.1993

46. Corral J, Castells X, Molins E, Chiarello P, Borras JM, Cots F. Long-term costs of colorectal cancer treatment in Spain. BMC Health Serv Res. 2016; 16(1):56. http://dx.doi.org/10.1186/s12913-016-1297-6

47. Rocconi RP, Case AS, Straughn JM Jr, Estes JM, et al. Role of chemotherapy for patients with recurrent platinum-resistant advanced epithelial ovarian cancer: a cost-effectiveness analysis. Cancer. 2006; 107(3):536-43.

48. Tournigand C, Andre T, Achille E, Lledo G, Flesh M, Mery-Mignard D, et al. FOLFIRI followed by FOLFOX6 or the reverse sequence in advanced colorectal cancer: a randomized GERCOR Study. J Clin Oncol. 2004; 22(2):229-37. http://dx.doi.org/10.1200/ JCO.2004.05.113

49. Jimeno A, Messersmith WA, Hirsch FR, Franklin WA, Eckhardt SG. KRAS mutations and sensitivity to epidermal growth factor receptor inhibitors in colorectal cancer: practical application of patient selection. J Clin Oncol. 2009;27(7):1130-6. http://dx.doi. org/10.1200/JCO.2008.19.8168 